BMJ Open

Sport \&

Exercise

Medicine

\title{
Muscle function is associated with future patient-reported outcomes in young adults with ACL injury
}

\author{
Vala Flosadottir, ${ }^{1}$ Ewa M Roos, ${ }^{2}$ Eva Ageberg ${ }^{1}$
}

To cite: Flosadottir V, Roos EM, Ageberg E. Muscle function is associated with future patient-reported outcomes in young adults with ACL injury. BMJ Open Sport Exerc Med 2016;2: e000154. doi:10.1136/ bmjsem-2016-000154

- Prepublication history for this paper is available online. To view these files please visit the journal online (http://dx.doi.org/10.1136/ bmjsem-2016-000154).

Accepted 10 August 2016 CrossMark

\footnotetext{
${ }^{1}$ Department of Health Sciences, Lund University, Lund, Sweden

${ }^{2}$ Research Unit for Musculoskeletal Function and Physiotherapy, Institute of Sports and Clinical Biomechanics, University of Southern Denmark, Odense, Denmark
}

Correspondence to Vala Flosadottir; vala.flosadottir@med.lu.se

\section{ABSTRACT}

Background/aim: Consequences of an anterior cruciate ligament $(A C L)$ injury include worse patientreported outcomes (PROs) and a decrease in activity level. Muscle function can be improved by targeted exercise. Our aims were to investigate cross-sectional and longitudinal associations among lower extremity muscle function and PROs after ACL injury.

Methods: Fifty-four participants (15 women, mean 30 years) with $A C L$ injury or reconstruction, from the Knee Anterior Cruciate Ligament, Nonsurgical versus Surgical Treatment (KANON) trial (ISRCTN84752559), were assessed with hop performance, muscle power and postural orientation 3 years (SD 0.85) after ACL injury. PROs at 3 and 5 years after injury included Knee Injury and Osteoarthritis Outcome Score (KOOS) subscales Function in sport and recreation (KOOS Sport/rec) and Knee-related Quality of life (KOOS QoL), KOOS item Q3 (KOOS Q3), Tegner Activity Scale and Activity Rating Scale (ARS). Partial Spearman's rankorder correlation was used to analyse correlations between muscle function and PROs, controlling for gender and treatment.

Results: Numerous cross-sectional correlations were observed between muscle function and PROs $\left(r_{s p} \approx 0.3-0.5, p \leq 0.045\right)$. Worse hop performance and worse postural orientation were associated with worse KOOS scores 2 years later $\left(r_{s p} \geq 0.280, p \leq 0.045\right)$. Worse muscle power was associated with lower future ARS scores $\left(r_{\mathrm{sp}}=0.281, \mathrm{p}=0.044\right)$.

Conclusions: The moderate associations suggest that improving muscle function during rehabilitation could improve present and future PROs.

\section{INTRODUCTION}

Treatment of anterior cruciate ligament (ACL) injury includes individualised rehabilitation, with or without additional reconstruction of the ACL (ACLR), with the goal of improving knee stability, muscle function and patient-reported outcomes (PROs). ${ }^{1}$ Despite treatment, knee-specific PROs seldom reach preinjury levels or levels of reference values of age-matched and sexmatched population-based group. ${ }^{2-4}$

\section{Summary box}

- Optimising muscle function during rehabilitation could potentially be important for present and future self-reported knee function and kneespecific activity level.

- Single-leg hop performance and postural orientation were more important aspects of muscle function than muscle strength for future knee function.

- Muscle function was more associated with the frequency of performing knee-demanding activities (Activity Rating Scale) than the level of sport-specific activity (Tegner Activity Scale), particularly cross-sectionally.

Knee-specific PROs reflect the patient's perspective on how the knee injury affects their daily life, including symptoms, function, quality of life and activity level. ${ }^{5}$ Unsuccessful outcome, such as poor knee function and pain, can result in direct and indirect costs for the individual and the society. ${ }^{6}$ Therefore, it is important to determine modifiable factors that may improve PRO scores in people with ACL injury. Muscle function may be one such modifiable factor.

Cross-sectional studies have shown that impairments in muscle function are associated with worse knee function after ACL injury. ${ }^{7-9}$ However, the causal relationship between muscle function and PRO scores cannot be established in cross-sectional studies. There have been few longitudinal, prospective studies reporting the short-term and long-term relationships between muscle function and PROs after ACL injury. ${ }^{10-14}$ Four of these studies reported that better functional performance, measured at different time points after injury or ACLR, predicted better self-reported knee function at follow-up at $1,{ }^{11-13} 2^{14}$ or $5^{13}$ years. One study observed no associations between muscle function and future self-reported knee function. ${ }^{10}$ Times for assessing muscle function 
Table 1 Characteristics of all participants

\begin{tabular}{lccc}
\hline & All $(\mathbf{n = 5 4})$ & Non-surgical $(\mathbf{n}=\mathbf{1 8})$ & Surgical $(\mathbf{n}=\mathbf{3 6})$ \\
\hline Age (years), mean (SD) & $29.7(5.3)$ & $28.6(5.2)$ & $30.3(5.3)$ \\
Women, $\mathrm{n}(\%)$ & $15(28)$ & $6(33)$ & $9(25)$ \\
BMI $\left(\mathrm{kg} / \mathrm{m}^{2}\right)$, mean (SD) & $24.6(3.4)$ & $24.7(3.0)$ & $24.5(3.6)$ \\
Autograft type & & & $20(56)$ \\
PT, $\mathrm{n}(\%)$ & & & $16(44)$ \\
$\quad$ HT, $\mathrm{n}(\%)$ & $1.8(0.80)$ & $1.9(0.64)$ & $1.8(0.88)$ \\
Time between 3 years and 5 years follow-ups (years), mean (SD) & &
\end{tabular}

and follow-up with PRO scores differ between these studies. Assessing muscle function at least 2 years after ACL injury may be an optimal time point for studying its relation to future PRO scores, because muscle function appears to improve up to $\sim 2$ years after injury/ACLR, and appears to be sustained at medium term follow-up. ${ }^{15}$

We aimed to investigate the cross-sectional and longitudinal associations between lower extremity muscle function and PRO scores after ACL injury/ACLR.

\section{METHODS}

\section{Participants}

The cohort, consisting of 54 participants ${ }^{16}$ (table 1), originates from the Knee Anterior Cruciate Ligament, Nonsurgical versus Surgical Treatment (KANON) study (ISRCTN84752559), ${ }^{1}$ a randomised controlled trial including 121 physically active participants suffering an acute ACL injury. The KANON study compared two forms of ACL treatments, both consisting of structured rehabilitation combined with either an early ACLR or the option of a later ACLR. ${ }^{1}$ The present subcohort of the KANON study underwent extensive testing of muscle function at 3 years, including hop and muscle strength test batteries, ${ }^{16}$ and postural orientation during functional tasks ${ }^{17}$ at mean 3 years, and PROs at mean 3 and 5 years, ${ }^{17} 18$ after injury/ACLR. The study was approved by the Research Ethics Committee at Lund University, and all participants gave their written informed consent.

\section{Assessment of muscle function}

Assessment of muscle function in terms of hop performance, muscle power and postural orientation was performed at mean 3 years (SD 0.85) (table 2). ${ }^{16} 19$

\section{Hop performance}

The hop test battery consisted of the following tests as previously described: ${ }^{16}$ single-leg vertical hop where the maximum jump height $(\mathrm{cm})$ was measured by the use of an infrared contact mat (Muscle Laboratory; Ergotest Technology, Oslo, Norway), the one leg hop for distance $(\mathrm{cm})$ where the participant jumped as far as possible by taking off and landing on one leg and the side hop where the participant was to jump from side to side as

\begin{tabular}{|c|c|c|}
\hline & $\begin{array}{l}\text { 3-year } \\
\text { follow-up }\end{array}$ & $\begin{array}{l}\text { 5-year } \\
\text { follow-up }\end{array}$ \\
\hline \multicolumn{3}{|l|}{ PROs } \\
\hline KOOS Pain $(0-100)$ & $88(14)$ & $89(13)$ \\
\hline KOOS Sport/rec $(0-100)$ & $75(25)$ & $73(25)$ \\
\hline KOOS QoL (0-100) & $66(25)$ & $67(25)$ \\
\hline KOOS Q3 (0-4), median (IQR) & $1(0-2)$ & $1(0-2)$ \\
\hline TAS (0-10), median (IQR) & $4(2-6)$ & $4(2-6)$ \\
\hline ARS (0-16), median (IQR) & $6(1-9)$ & $3(1-8)$ \\
\hline \multicolumn{3}{|l|}{ Muscle power tests, mean (SD) } \\
\hline \multicolumn{3}{|l|}{ Knee extension } \\
\hline Injured leg (W) & $239(81)$ & \\
\hline LSI (\%) & $94(13)$ & \\
\hline \multicolumn{3}{|l|}{ Knee flexion* } \\
\hline LSI (\%) & $98(14)$ & \\
\hline \multicolumn{3}{|l|}{ Leg press } \\
\hline LSI (\%) & $100(14)$ & \\
\hline \multicolumn{3}{|l|}{ Hop tests } \\
\hline \multicolumn{3}{|l|}{ Vertical hop } \\
\hline Injured leg (cm) & $16(4)$ & \\
\hline LSI (\%) & 97 (14) & \\
\hline \multicolumn{3}{|l|}{ Side hop } \\
\hline Injured leg (n) & $37(15)$ & \\
\hline LSI (\%) & $93(23)$ & \\
\hline \multicolumn{3}{|l|}{ One leg hop } \\
\hline LSI (\%) & $99(8)$ & \\
\hline \multicolumn{3}{|l|}{ Postural orientation } \\
\hline TSP total score injured leg* & $4(4)$ & \\
\hline \multicolumn{3}{|c|}{$\begin{array}{l}\text { The possible range of scores for the PROs is specified in } \\
\text { parentheses. Values are mean and SD unless otherwise indicated. } \\
\text { *One participant did not perform the test. } \\
\text { ARS, activity rating scale for disorders of the knee; KOOS, the } \\
\text { Knee Injury and Osteoarthritis Outcome Score- function in sport } \\
\text { and recreation (Sport/rec), knee-related quality of life (QoL), knee } \\
\text { confidence (Q3); PRO, patient-reported outcome; LSI, limb } \\
\text { symmetry; TAS, Tegner Activity scale; TSP, Test for Substitution } \\
\text { Patterns; W, watt. }\end{array}$} \\
\hline
\end{tabular}

many times as possible outside of a $40 \mathrm{~cm}$ wide area marked on the floor during a period of $30 \mathrm{~s}$.

\section{Muscle strength}

The muscle strength tests included quadriceps muscle power through a knee extension test (from $110^{\circ}$ knee flexion to full extension), hamstring muscle power in a knee flexion test (from full knee extension to $110^{\circ}$ knee 
flexion) and lower extremity muscle power with a leg press test (from $90^{\circ}$ knee and hip flexion to fully extended knee and $30^{\circ}$ hip flexion) as described. ${ }^{16}$ The tests were performed in weight training machines intended for knee extension, knee flexion and leg press, respectively, where the average power output (W) was recorded using a computerised system (Muscle Laboratory; Ergotest Technology). ${ }^{16}$

Absolute values $(\mathrm{W}, \mathrm{cm}$ ) and Limb Symmetry Index (LSI) values were used in the analysis of the hop and muscle power tests. LSI represents the percentage difference between the absolute value of the injured and the uninjured legs where an $\mathrm{LSI} \geq 90 \%$ is considered normal. ${ }^{15}$

\section{Postural orientation}

Postural orientation was visually rated during the performance of five functional tasks with the Test for Substitution Patterns (TSP): 'Body weight-altering test', 'Tip-toe standing knee flexion', 'Knee flexion-extension standing on one leg', 'Forward lunge from stairs' and 'Mini-squat'. ${ }^{17}$ The TSP includes a total score for all the tasks based on the orientation of several body segments. The total TSP scores could range from 0 to 54 points with lower scores indicating better results. The TSP has shown good inter-reliability and intrareliability. ${ }^{19}$

For postural orientation, the absolute values for the injured leg (TSP total score) and the difference between the absolute values of the injured and the uninjured leg (TSP diff) were used in the analysis.

\section{Patient-reported outcomes}

The participants reported their knee function and kneespecific activity level at the same occasion as the assessment of muscle function and at a 5-year follow-up (table 2).

\section{Knee function}

The participants reported their knee function through the Swedish version ${ }^{20}$ of the Knee Injury and Osteoarthritis Outcome Score (KOOS), which is valid and reliable for individuals with ACL injury/reconstruction. $^{21}$ The KOOS contains five subscales, covering pain, symptoms, activities of daily living, function in sports and recreational activities, and quality of life, with separate normalised scores ranging from 0 (worst) to 100 (best). The subscales Pain (KOOS Pain), Function in sport and recreation (KOOS Sport/rec) and Knee-related Quality of life (KOOS QoL) were included in the analysis. The item Q3 from the subscale QoL, where patients report trouble with lack of knee confidence on a score from 0 (no at all) to 4 (extremely troubled), has been reported at 3 years ${ }^{8}$ and was in the present study included in the longitudinal analyses.

\section{Knee-specific activity}

The participants rated their knee activity level using the Tegner Activity Scale (TAS) and the Activity Rating Scale (ARS) for disorders of the knee. ${ }^{5}$ The TAS is designed to evaluate individuals with knee injury and their level of activity based on specific sports participation and/or line of work. The TAS ranges from 0 (sick leave or disability due to knee problems) to 10 (participation in competitive sports at a national or international level). The TAS is valid and reliable for assessing activity level in individuals with knee conditions, that is, ACL injury. ${ }^{5}$ The ARS evaluates the level of activity with focus on several components of physical function required in different sports. This score rates the frequency of participation in four separate activities with high demands on knee function: running, cutting, decelerating and pivoting, each analysed separately. Each item is graded on a five-level scale from 'none' to ' 4 or more times a week' and a total score from 16 (most frequent participation) to 0 (no participation) is calculated. The ARS is valid and reliable for evaluation of activity level among individuals with knee disorders, including ligament injury. ${ }^{5}$

\section{Statistical analysis}

Statistical analyses were performed using IBM SPSS for Windows, V.22.0 (IBM Corp., Armonk, New York, USA). Spearman's rank-order correlation analysis was used to test the associations between the muscle function tests. Any correlations above 0.8 between two muscle function tests resulted in the exclusion of one of the tests; the knee flexion (W), the leg press (W) and the one leg hop tests were excluded based on previous findings showing higher sensitivity for the knee extension and the side hop tests. ${ }^{16}$ The correlation between TSP difference and TSP total $>0.90$, thus the injured leg, was sufficient to be included in further analysis. Spearman's and partial Spearman's rank-order correlation analyses were used to assess the cross-sectional (3-year) and longitudinal (5-year) associations between muscle function and PROs, controlling for gender and treatment (surgical/ non-surgical). Correlation coefficient thresholds suggested by Cohen $^{22}$ were used; correlation coefficients $\geq 0.10$ to 0.29 represent low association, $\geq 0.30$ to 0.49 moderate association and coefficients $\geq 0.50$ large association. Wilcoxon signed ranks test was used to examine changes in PROs scores from 3 to 5 years. The study had an exploratory character and therefore no adjustments for multiple comparisons were made. $\mathrm{p}$ Values $\leq 0.05$ were considered statistically significant.

\section{RESULTS}

The correlations between the muscle function tests are presented in table 3. Muscle function test scores and PRO scores are listed in table 2.

Several associations between muscle function and PROs above 0.1 were noted but no correlation coefficients equal to or above 0.5 were observed (tables 4 and 5 ). The unadjusted and adjusted (gender and treatment) correlation coefficients were quite similar; therefore, only the adjusted results are given. 


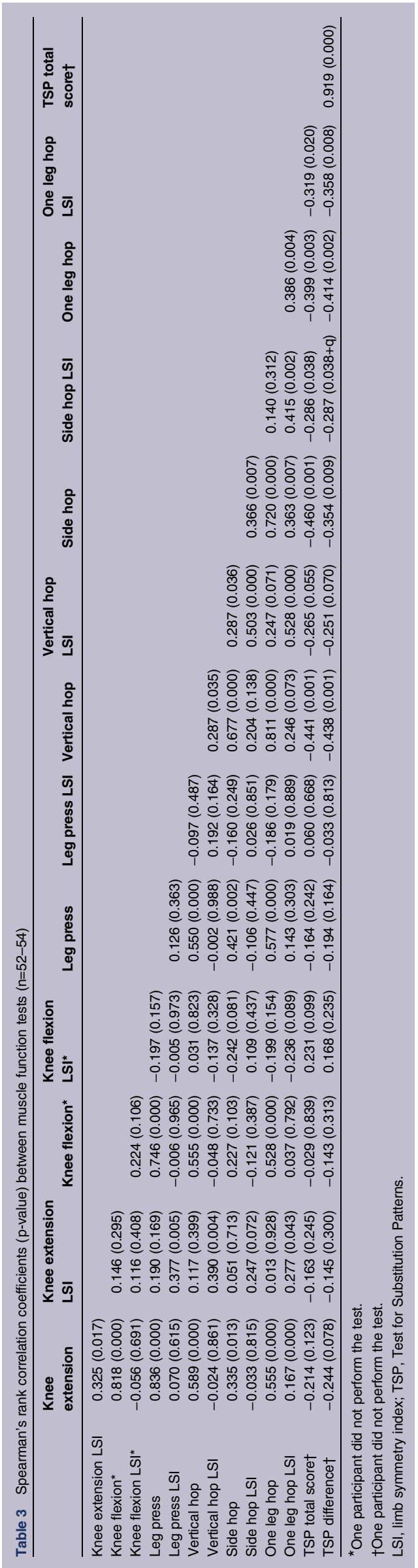

Changes in PRO scores between 3 and $\mathbf{5}$ years

There were no statistically significant changes in the KOOS scores between 3 and 5 years (KOOS Pain -1 ( $95 \%$ CI -3 to 2), KOOS Sport/rec 2 (95\% CI -3 to 7 ) and KOOS QoL -6 (95\% CI -6 to 3$))$. Ten (19\%) participants reported worse scores in the KOOS Q3, 15 $(28 \%)$ in the TAS and $22(41 \%)$ in the ARS at 5 years compared with 3 years.

\section{Cross-sectional associations between muscle function and PRO scores}

Knee function

Worse vertical hop (cm, LSI) and TSP total score were associated with worse scores on KOOS Pain $\left(r_{s p} \geq 0.302\right.$, $\mathrm{p} \leq 0.031)$. Worse vertical hop $(\mathrm{cm})$, side hop (n, LSI) and TSP total score were associated with worse scores on KOOS Sport/rec $\left(\mathrm{r}_{\mathrm{sp}} \geq 0.320, \mathrm{p} \leq 0.021\right)$. Worse knee extension power (LSI), vertical hop (LSI, cm), side hop (LSI) and TSP total score were associated with worse $\operatorname{KOOS}$ QoL $\left(\mathrm{r}_{\mathrm{sp}} \geq 0.314, \mathrm{p} \leq 0.023\right)$.

\section{Knee-specific activity}

Worse knee extension power (W), vertical hop $(\mathrm{cm})$, side hop (n, LSI) and TSP total score were associated with lower ARS score $\left(r_{\mathrm{sp}} \geq 0.330, \mathrm{p} \leq 0.017\right)$. Worse TSP total score was associated with lower TAS score $\left(r_{\mathrm{sp}}\right.$ $=0.329, \mathrm{p}=0.018)$.

\section{Longitudinal associations between muscle function and PROs}

About one-third of the associations in the cross-sectional analyses (table 4) remained in the longitudinal analyses (table 5).

\section{Knee function}

Worse vertical hop $(\mathrm{cm})$ was associated with worse scores on KOOS Pain $\left(\mathrm{r}_{\mathrm{sp}}=0.308, \mathrm{p}=0.026\right)$. Worse side hop LSI was associated with worse KOOS Sport/rec $\left(r_{\mathrm{sp}}=0.280\right.$, $\mathrm{p}=0.045)$. Worse vertical hop (LSI, $\mathrm{cm}$ ) was associated with worse KOOS QoL $\left(r_{\mathrm{sp}}=0.281, \mathrm{p}=0.044\right.$ and $\mathrm{r}_{\mathrm{sp}}$ $=0.284, \mathrm{p}=0.041$, respectively). Worse TSP total score was associated with worse KOOS QoL $\left(\mathrm{r}_{\mathrm{sp}}=0.334, \mathrm{p}=0.017\right)$. Worse vertical hop LSI and worse TSP total score were associated with worse KOOS Q3 $\left(\mathrm{r}_{\mathrm{sp}}=-0.324, \mathrm{p}=0.019\right.$ and $\mathrm{r}_{\mathrm{sp}}=0.372, \mathrm{p}=0.007$, respectively).

\section{Knee-specific activity}

Worse knee extension power (W) was associated with lower ARS score $\left(\mathrm{r}_{\mathrm{sp}}=0.281, \mathrm{p}=0.044\right)$.

\section{DISCUSSION}

Several moderate correlations $\left(\mathrm{r}_{\mathrm{sp}} \approx 0.3\right.$ to 0.5$)$ were observed in the cross-sectional and the longitudinal analyses between muscle function and PROs. In the longitudinal analysis, worse hop performance and worse postural orientation were associated with worse future 
Table 4 Spearman's rank-order correlations $\left(r_{s}\right)$ and rank-order partial correlations $\left(r_{s p}\right)$ between muscle function and PROs at 3 years

\begin{tabular}{|c|c|c|c|c|c|c|c|c|c|c|c|c|}
\hline & \multicolumn{8}{|c|}{ Knee function } & \multicolumn{4}{|c|}{ Knee-specific activity } \\
\hline & \multicolumn{2}{|c|}{ KOOS Pain } & \multicolumn{2}{|c|}{ KOOS Sport/rec } & \multicolumn{2}{|c|}{ KOOS QoL } & \multicolumn{2}{|c|}{ KOOS Q3 } & \multicolumn{2}{|l|}{ TAS } & \multicolumn{2}{|l|}{ ARS } \\
\hline & $\overline{r_{s} / r_{s p}}$ & p Value & $\overline{r_{s} / r_{s p}}$ & p Value & $\overline{r_{s} / r_{s p}}$ & p Value & $\overline{r_{s} / r_{s p}}$ & p Value & $\overline{r_{s} / r_{s p}}$ & p Value & $\overline{r_{s} / r_{s p}}$ & p Value \\
\hline Knee ext $(W)$ & 0.010 & 0.941 & 0.182 & 0.189 & 0.097 & 0.485 & 0.139 & 0.315 & 0.278 & 0.042 & 0.010 & 0.941 \\
\hline Knee ext $(W)^{*}$ & 0.087 & 0.540 & 0.146 & 0.302 & 0.186 & 0.186 & 0.110 & 0.440 & 0.331 & 0.017 & 0.087 & 0.540 \\
\hline Knee ext LSI (\%) & 0.245 & 0.074 & 0.121 & 0.383 & 0.345 & 0.011 & 0.142 & 0.304 & 0.262 & 0.056 & 0.245 & 0.074 \\
\hline Knee ext LSI (\%)* & 0.246 & 0.079 & 0.144 & 0.307 & 0.339 & 0.014 & 0.153 & 0.278 & 0.272 & 0.052 & 0.246 & 0.079 \\
\hline Knee flex LSI (\%) & 0.038 & 0.790 & 0.031 & 0.823 & 0.055 & 0.695 & -0.003 & 0.986 & 0.061 & 0.664 & 0.038 & 0.790 \\
\hline Knee flex LSI (\%)* & 0.033 & 0.817 & 0.033 & 0.819 & 0.062 & 0.665 & 0.003 & 0.984 & 0.066 & 0.643 & 0.033 & 0.817 \\
\hline Leg press LSI (\%) & 0.163 & 0.238 & 0.057 & 0.684 & 0.037 & 0.792 & -0.146 & 0.291 & 0.111 & 0.424 & 0.163 & 0.238 \\
\hline Leg press LSI (\%)* & 0.145 & 0.305 & 0.041 & 0.771 & 0.064 & 0.652 & -0.150 & 0.289 & 0.127 & 0.370 & 0.145 & 0.305 \\
\hline Vertical hop (cm) & 0.231 & 0.093 & 0.429 & 0.001 & 0.255 & 0.063 & 0.161 & 0.246 & 0.309 & 0.023 & 0.231 & 0.093 \\
\hline Vertical hop $(\mathrm{cm})^{*}$ & 0.333 & 0.016 & 0.458 & 0.001 & 0.343 & 0.013 & 0.135 & 0.339 & 0.330 & 0.017 & 0.333 & 0.016 \\
\hline Vertical hop LSI (\%) & 0.324 & 0.017 & 0.238 & 0.083 & 0.350 & 0.009 & 0.134 & 0.334 & 0.230 & 0.094 & 0.324 & 0.017 \\
\hline Vertical hop LSI (\%)* & 0.318 & 0.021 & 0.263 & 0.060 & 0.351 & 0.011 & 0.149 & 0.293 & 0.243 & 0.082 & 0.318 & 0.021 \\
\hline Side hop (n) & 0.167 & 0.227 & 0.330 & 0.015 & 0.123 & 0.376 & 0.182 & 0.187 & 0.409 & 0.002 & 0.167 & 0.227 \\
\hline Side hop $(n)^{\star}$ & 0.201 & 0.152 & 0.320 & 0.021 & 0.143 & 0.310 & 0.164 & 0.246 & 0.409 & 0.003 & 0.201 & 0.152 \\
\hline Side hop LSI (\%) & 0.258 & 0.059 & 0.298 & 0.028 & 0.334 & 0.014 & 0.219 & 0.112 & 0.341 & 0.012 & 0.258 & 0.059 \\
\hline Side hop LSI (\%)* & 0.272 & 0.051 & 0.380 & 0.005 & 0.314 & 0.023 & 0.255 & 0.068 & 0.376 & 0.006 & 0.272 & 0.051 \\
\hline One leg hop LSI (\%) & -0.152 & 0.272 & -0.059 & 0.671 & 0.009 & 0.948 & 0.198 & 0.152 & 0.061 & 0.660 & -0.152 & 0.272 \\
\hline One leg hop LSI (\%)* & -0.146 & 0.300 & -0.054 & 0.702 & 0.003 & 0.984 & 0.199 & 0.158 & 0.061 & 0.669 & -0.146 & 0.300 \\
\hline TSP total score & -0.281 & 0.041 & -0.426 & 0.001 & -0.400 & 0.003 & -0.343 & 0.012 & -0.368 & 0.007 & -0.281 & 0.041 \\
\hline TSP total score* & -0.302 & 0.031 & -0.412 & 0.003 & -0.430 & 0.002 & -0.329 & 0.018 & -0.365 & 0.008 & -0.302 & 0.031 \\
\hline
\end{tabular}

Bold numbers represent moderate correlations. Italic numbers represent close to moderate correlations. All assessment scores (except LSI) originate from the injured leg.

*Muscle function effect independent of gender and treatment.

ARS, Activity Rating Scale for disorders of the knee; KOOS, the Knee Injury and Osteoarthritis Outcome Score-function in sport and

recreation (Sport/rec), knee-related quality of life (QoL), knee confidence (Q3); LSI, limb symmetry index; TAS, Tegner Activity scale; TSP,

Test for Substitution Patterns; W, watt.

knee function, and worse knee extension muscle was associated with lower future knee-specific activity.

\section{Cross-sectional and Iongitudinal associations}

Fewer and weaker associations were observed in the longitudinal compared to the cross-sectional analyses. Specifically, there was a marked decrease in the number of associations between muscle function and future selfreported pain and function in sports and recreational activities (KOOS subscales Pain and Sport/rec) as well as future knee-specific activity level (TAS and ARS). In the longitudinal analysis, worse vertical hop performance and worse postural orientation were associated with worse future knee-related quality of life and worse knee confidence (KOOS QoL and Q3). Although no statistically significant differences were observed in PROs scores between 3 and 5 years in the present cohort, possibly due to the small sample size, there may be several explanations for the differences in the cross-sectional and the longitudinal results. During the follow-up period, the participants may have modified their activities or activity level, ${ }^{23} 24$ or they may have had a change of perspectives due to adaptation or acceptance. ${ }^{25}$ Contextual factors, such as social or lifestyle changes, are additional plausible explanations. ${ }^{26-28}$

\section{Knee function}

Worse vertical hop performance $(\mathrm{cm})$ was associated with more future self-reported knee pain (KOOS subscale Pain). Self-reported knee pain is a significant clinical sign of symptomatic knee osteoarthritis (OA). ${ }^{29}$ Previous reports suggest that impairments in muscle function and knee injury constitute risk factors for future knee OA. ${ }^{30} 31$

We observed that worse performance in the vertical hop (cm, LSI), side hop (LSI) and TSP was associated with worse scores on the KOOS subscales Sport/rec, QoL and item Q3. In line with our findings, worse single-leg hop for distance performance, performed at mean 2.5 months after ACL injury, was associated with worse future scores on the IKDC 2000 at 1 year after injury. ${ }^{11}$ In surgically treated patients, single-leg hop tests (the $6 \mathrm{~m}$ timed hop test and the crossover hop), conducted 6 months after ACLR, predicted worse IKDC 2000 scores 6 months later. ${ }^{12}$ In another report from the KANON-trial, worse one leg rise (LSI) performance, assessed by the treating clinician when rehabilitation was completed at mean 8 after ACL injury or mean 11 months after ACLR, predicted worse $\mathrm{KOOS}_{4}$ scores (mean score of the subscales Pain, Symptoms, Sport/rec and QoL) at 2 and 5 years. ${ }^{13}$ The assessment of muscle function was performed by the treating clinician and was not as rigorous or extensive as in the present cohort. $^{13}$ In only one study, there were no associations between knee muscle strength and single-leg hop for distance assessed at 2 years after ACLR and scores on the KOOS subscales Sport/rec and QoL 9.5 years later. ${ }^{10}$ The long time to follow-up ${ }^{10}$ may have induced several other factors affecting the outcome. 
Table 5 Spearman's rank-order correlations $\left(r_{s}\right)$ and rank-order partial correlations $\left(r_{s p}\right)$ between muscle function and future PROs at 5 years

\begin{tabular}{|c|c|c|c|c|c|c|c|c|c|c|c|c|}
\hline & \multicolumn{8}{|c|}{ Knee function } & \multicolumn{4}{|c|}{ Knee-specific activity } \\
\hline & \multicolumn{2}{|c|}{ KOOS Pain } & \multicolumn{2}{|c|}{ KOOS Sport/rec } & \multicolumn{2}{|c|}{ KOOS QoL } & \multicolumn{2}{|c|}{ KOOS Q3 } & \multicolumn{2}{|l|}{ TAS } & \multicolumn{2}{|l|}{ ARS } \\
\hline & $\mathbf{r}_{\mathbf{s}} / \mathbf{r}_{\mathrm{sp}}$ & p Value & $\mathbf{r}_{\mathbf{s}} / \mathbf{r}_{\mathrm{sp}}$ & p Value & $r_{s} / r_{s p}$ & p Value & $r_{s} / r_{s p}$ & p Value & $\mathbf{r}_{\mathbf{s}} / \mathbf{r}_{\mathbf{s p}}$ & p Value & $\mathbf{r}_{s} / r_{s p}$ & p Value \\
\hline Knee ext (W) & 0.049 & 0.723 & 0.209 & 0.129 & 0.206 & 0.135 & -0.275 & 0.044 & 0.215 & 0.119 & 0.321 & 0.018 \\
\hline Knee ext $(W)^{*}$ & 0.105 & 0.461 & 0.098 & 0.489 & 0.187 & 0.184 & -0.233 & 0.097 & -0.012 & 0.934 & 0.281 & 0.044 \\
\hline Knee ext LSI (\%) & 0.148 & 0.284 & 0.031 & 0.823 & 0.198 & 0.151 & -0.263 & 0.054 & 0.026 & 0.853 & 0.173 & 0.210 \\
\hline Knee ext LSI (\%)* & 0.145 & 0.306 & 0.050 & 0.726 & 0.203 & 0.148 & -0.272 & 0.051 & 0.046 & 0.745 & 0.182 & 0.196 \\
\hline Knee flex LSI (\%) & 0.035 & 0.801 & -0.131 & 0.351 & -0.063 & 0.652 & 0.116 & 0.408 & 0.224 & 0.106 & -0.007 & 0.959 \\
\hline Knee flex LSI (\%)* & 0.038 & 0.791 & -0.123 & 0.391 & -0.051 & 0.720 & 0.097 & 0.498 & 0.261 & 0.064 & 0.011 & 0.939 \\
\hline Leg press LSI (\%) & 0.017 & 0.903 & -0.064 & 0.647 & -0.009 & 0.949 & 0.053 & 0.706 & -0.162 & 0.241 & 0.044 & 0.750 \\
\hline Leg press LSI (\%)* & 0.021 & 0.881 & -0.036 & 0.800 & 0.040 & 0.778 & -0.052 & 0.715 & -0.088 & 0.533 & 0.139 & 0.326 \\
\hline Vertical hop (cm) & 0.233 & 0.090 & 0.229 & 0.096 & 0.290 & 0.033 & -0.292 & 0.032 & 0.103 & 0.459 & 0.154 & 0.266 \\
\hline Vertical hop $(\mathrm{cm})^{\star}$ & 0.308 & 0.026 & 0.145 & 0.305 & 0.281 & 0.044 & -0.246 & 0.078 & -0.097 & 0.496 & 0.058 & 0.683 \\
\hline Vertical hop LSI (\%) & 0.251 & 0.067 & 0.104 & 0.453 & 0.264 & 0.054 & -0.285 & 0.037 & -0.110 & 0.430 & -0.018 & 0.898 \\
\hline Vertical hop LSI (\%)* & 0.249 & 0.075 & 0.136 & 0.337 & 0.284 & 0.041 & -0.324 & 0.019 & -0.071 & 0.616 & 0.008 & 0.954 \\
\hline Side hop (n) & 0.121 & 0.382 & 0.164 & 0.236 & 0.139 & 0.317 & -0.153 & 0.270 & 0.060 & 0.668 & 0.228 & 0.097 \\
\hline Side hop $(n)^{*}$ & 0.139 & 0.327 & 0.109 & 0.443 & 0.109 & 0.440 & -0.105 & 0.459 & -0.045 & 0.752 & 0.181 & 0.199 \\
\hline Side hop LSI (\%) & 0.254 & 0.064 & 0.221 & 0.108 & 0.248 & 0.071 & -0.165 & 0.232 & 0.182 & 0.188 & 0.145 & 0.294 \\
\hline Side hop LSI (\%)* & 0.250 & 0.074 & 0.280 & 0.045 & 0.256 & 0.067 & -0.154 & 0.306 & 0.233 & 0.096 & 0.145 & 0.306 \\
\hline One leg hop LSI (\%) & -0.086 & 0.535 & -0.067 & 0.631 & 0.056 & 0.689 & -0.142 & 0.307 & -0.039 & 0.777 & 0.019 & 0.894 \\
\hline One leg hop LSI (\%)* & -0.088 & 0.536 & -0.075 & 0.598 & 0.046 & 0.746 & -0.122 & 0.388 & -0.062 & 0.665 & -0.001 & 0.993 \\
\hline TSP total score & -0.195 & 0.162 & -0.307 & 0.025 & -0.340 & 0.013 & 0.375 & 0.006 & -0.057 & 0.686 & 0.003 & 0.998 \\
\hline TSP total score* & -0.212 & 0.135 & -0.274 & 0.052 & -0.334 & 0.017 & 0.372 & 0.007 & 0.008 & 0.955 & 0.035 & 0.806 \\
\hline
\end{tabular}

Bold numbers represent moderate correlations. Italic numbers represent close to moderate correlations. All assessment scores (except LSI) originate from the injured leg.

*Muscle function effect independent of gender and treatment.

ARS, Activity Rating Scale for disorders of the knee; KOOS, the Knee Injury and Osteoarthritis Outcome Score-function in sport and

recreation (Sport/rec), knee-related quality of life (QoL), knee confidence (Q3); LSI, limb symmetry index; TAS, Tegner Activity scale; TSP,

Test for Substitution Patterns; W, watt.

Taken together, despite temporal differences in muscle function assessment, various tests of muscle function and PRO scores, and difference in time to follow-up, our study and previous studies ${ }^{11-13}$ indicate that worse muscle function is associated with worse future knee function. This stresses the possibility that optimising muscle function during rehabilitation may improve future PRO scores.

\section{Knee-specific activity level}

Our results indicated that worse knee extension power (W) was associated with lower frequency of performing knee-demanding activities, measured with the ARS. One explanation for this may be that the ability to generate high forces during high movement velocities is an important factor in physical and athletic performance. ${ }^{32}$ A recent study showed that worse hop performance LSI (single-leg and triple hop for distance), assessed 1 year after ACLR, was related to lower rates of return to preinjury sport level 1 year later. ${ }^{14}$

Sousa $e t a l^{33}$ reported that lower muscle strength (isokinetic quadriceps and hamstring strength) and worse hop performance (vertical jump, single-leg hop and triple jump), assessed at 6 months after ACLR, were associated with lower activity level measured with the TAS at mean 4 years after ACLR. In our cohort, we found no association between hop performance at mean 3 years after ACL injury/ACLR and TAS or ARS at 5 years. The difference in time points for muscle function assessment and the difference in sample size between our study $(\mathrm{n}=54)$ and that by Sousa $e t a l^{33}(\mathrm{n}=223)$ may be explanations for the different results.

Muscle function was more associated with the frequency of performing knee-demanding activities (ARS) than the level of sport-specific activity (TAS). This suggests that individuals who are active in knee-demanding activities, such as pivoting and cutting sports, may especially benefit from optimised muscle function for present and future frequency of performing kneedemanding activities. To the best of our knowledge, this is the first study to prospectively investigate the associations between muscle function and the ARS in the population with ACL injury. The substantial difference in numbers of associations in the cross-sectional analyses compared to the longitudinal analyses may be explained by near half of the participants modifying their activities or activity level from 3 to 5 years.

\section{Strengths and limitations}

The main strength of our study is that the data originate from the KANON study, ${ }^{1}$ a rigorous randomised controlled trial and a well-designed cross-sectional cohort study, ${ }^{16}$ where extensive muscle function data were collected with reliable and valid measures. Muscle function was assessed at mean 3 years after ACL injury/ACLR, at a time point when optimal muscle function likely was reached. We report cross-sectional and longitudinal results contributing to a more comprehensive view of the 
role of muscle function for PROs. As recommended ${ }^{15}$ we report absolute values for the injured leg in all muscle function tests in addition to LSI values in the analyses of the hop and the muscle strength tests. A limitation is the moderate sample size $(n=54)$, compared to other studies $(\mathrm{n}=81-87) .{ }^{11-13}$ Furthermore, the time to follow-up did not allow for investigation of associations between muscle function and radiographic knee OA development. ${ }^{18}$

\section{Clinical implications}

Based on our results, rehabilitation of an ACL injury should include neuromuscular exercises aimed at optimising and maintaining good single-leg hop performance and postural orientation, particularly to improve future knee-related quality of life and knee confidence. This is important, since individuals with ACL injury report major problems within knee-related quality of life and knee confidence, when assessed with the KOOS. ${ }^{34}$ Furthermore, promoting good single-leg hop performance may reduce future self-reported knee pain, and potentially reduce the risk of knee OA. Optimising knee extension power may specifically be an important factor for individuals participating in knee-demanding activities. Our results further support the use of postural orientation as a measure of muscle function in addition to muscle strength and hop performance. ${ }^{8} 17$

\section{CONCLUSIONS}

Poor muscle function at 3 years was moderately associated with worse self-reported outcomes cross-sectionally and 2 years later, emphasising the potential importance of improving muscle function during the rehabilitation after ACL injury. Single-leg hop performance and postural orientation appeared to be more important aspects for future PRO scores than muscle strength.

\section{Twitter Follow Vala Flosadottir at @valaflosadottir}

Contributors All authors contributed to the study design. EA and EMR collected the data. VF was responsible for the analysis and interpretation of the data, and wrote the first draft of the manuscript. EA contributed in analysis and interpretation of data, contributed in writing the manuscript and provided feedback on drafts of this paper. EMR contributed in interpretation of data and critically revised the manuscript for important intellectual content. All authors approved the final manuscript.

Funding This research was funded by the Swedish Research Council (2009-1447), the Crafoord Foundation, the Swedish Rheumatism Association, the Swedish National Centre for Research in Sports and the Faculty of Medicine of Lund University. The original KANON study, from which the patients were included, was additionally supported by Pfizer Global Research, Thelma Zoegas Fund, the Swedish National Centre for Research in Sports and the Stig \& Ragna Gorthon Research Fund

Competing interests None declared.

Patient consent Obtained.

Ethics approval Research Ethics Committee at Lund University.

Provenance and peer review Not commissioned; externally peer reviewed.

Open Access This is an Open Access article distributed in accordance with the Creative Commons Attribution Non Commercial (CC BY-NC 4.0) license, which permits others to distribute, remix, adapt, build upon this work noncommercially, and license their derivative works on different terms, provided the original work is properly cited and the use is non-commercial. See: http:// creativecommons.org/licenses/by-nc/4.0/

\section{REFERENCES}

1. Frobell RB, Roos EM, Roos HP, et al. A randomized trial of treatment for acute anterior cruciate ligament tears. $N$ Engl J Med 2010;363:331-42

2. Ageberg E, Forssblad M, Herbertsson $\mathrm{P}$, et al. Sex differences in patient-reported outcomes after anterior cruciate ligament reconstruction: data from the Swedish knee ligament register. Am J Sports Med 2010;38:1334-42.

3. Ardern CL, Taylor NF, Feller JA, et al. Return-to-sport outcomes at 2 to 7 years after anterior cruciate ligament reconstruction surgery. Am J Sports Med 2012;40:41-8.

4. Filbay SR, Culvenor AG, Ackerman IN, et al. Quality of life in anterior cruciate ligament-deficient individuals: a systematic review and meta-analysis. Br J Sports Med 2015;49:1033-41.

5. Collins NJ, Misra D, Felson DT, et al. Measures of knee function: International Knee Documentation Committee (IKDC) Subjective Knee Evaluation Form, Knee Injury and Osteoarthritis Outcome Score (KOOS), Knee Injury and Osteoarthritis Outcome Score Physical Function Short Form (KOOS-PS), Knee Outcome Survey Activities of Daily Living Scale (KOS-ADL), Lysholm Knee Scoring Scale, Oxford Knee Score (OKS), Western Ontario and McMaster Universities Osteoarthritis Index (WOMAC), Activity Rating Scale (ARS), and Tegner Activity Score (TAS). Arthritis Care Res (Hoboken) 2011;63:S208-28.

6. Mather RC III, Koenig L, Kocher MS, et al. Societal and economic impact of anterior cruciate ligament tears. J Bone Joint Surg Am 2013;95:1751-9.

7. Reinke EK, Spindler KP, Lorring D, et al. Hop tests correlate with IKDC and KOOS at minimum of 2 years after primary ACL reconstruction. Knee Surg Sports Traumatol Arthrosc 2011;19:1806-16.

8. Ageberg E, Roos EM. The association between knee confidence and muscle power, hop performance, and postural orientation in people with anterior cruciate ligament injury. J Orthop Sports Phys Ther 2016;46:477-82.

9. Logerstedt D, Di Stasi S, Grindem H, et al. Self-reported knee function can identify athletes who fail return to activity criteria up to 1 year after anterior cruciate ligament reconstruction: a Delaware-Oslo ACL cohort study. J Orthop Sports Phys Ther 2014;44:914-23.

10. Möller E, Weidenhielm L, Werner S. Outcome and knee-related quality of life after anterior cruciate ligament reconstruction: a long-term follow-up. Knee Surg Sports Traumatol Arthrosc 2009;17:786-94.

11. Grindem H, Logerstedt D, Eitzen I, et al. Single-legged hop tests as predictors of self-reported knee function in nonoperatively treated individuals with anterior cruciate ligament injury. Am J Sports Med 2011;39:2347-54.

12. Logerstedt D, Grindem H, Lynch A, et al. Single-legged hop tests as predictors of self-reported knee function after anterior cruciate ligament reconstruction: the Delaware-Oslo ACL cohort study. Am J Sports Med 2012;40:2348-56.

13. Ericsson $Y B$, Roos EM, Frobell RB. Lower extremity performance following ACL rehabilitation in the KANON-trial: impact of reconstruction and predictive value at 2 and 5 years. $\mathrm{Br} J$ Sports Med 2013;47:980-5.

14. Ardern CL, Taylor NF, Feller JA, et al. Sports participation 2 years after anterior cruciate ligament reconstruction in athletes who had not returned to sport at 1 year: a prospective follow-up of physical function and psychological factors in 122 athletes. Am J Sports Med 2015;43:848-56.

15. Thomeé R, Kaplan Y, Kvist J, et al. Muscle strength and hop performance criteria prior to return to sports after $\mathrm{ACL}$ reconstruction. Knee Surg Sports Traumatol Arthrosc 2011;19:1798-805.

16. Ageberg E, Thomeé R, Neeter C, et al. Muscle strength and functional performance in patients with anterior cruciate ligament injury treated with training and surgical reconstruction or training only: a two to five-year followup. Arthritis Rheum 2008;59:1773-9.

17. Trulsson A, Roos EM, Ageberg E, et al. Relationships between postural orientation and self reported function, hop performance and muscle power in subjects with anterior cruciate ligament injury. BMC Musculoskelet Disord 2010;11:143. 
18. Frobell RB, Roos HP, Roos EM, et al. Treatment for acute anterior cruciate ligament tear: five year outcome of randomised trial. BMJ 2013;346:f232.

19. Trulsson A, Garwicz M, Ageberg E. Postural orientation in subjects with anterior cruciate ligament injury: development and first evaluation of a new observational test battery. Knee Surg Sports Traumatol Arthrosc 2010;18:814-23.

20. Roos EM, Roos HP, Ekdahl C, et al. Knee injury and Osteoarthritis Outcome Score (KOOS) - validation of a Swedish version. Scand J Med Sci Sports 1998;8:439-48.

21. Collins NJ, Prinsen CA, Christensen R, et al. Knee Injury and Osteoarthritis Outcome Score (KOOS): systematic review and meta-analysis of measurement properties. Osteoarthritis Cartilage 2016;24:1317-29.

22. Cohen J. Statistical power analysis for the behavioral sciences. 2nd edn. New Jersey: Lawrence Erlbaum Associates, Inc., 1988.

23. Kostogiannis I, Ageberg E, Neuman P, et al. Activity level and subjective knee function 15 years after anterior cruciate ligament injury: a prospective, longitudinal study of nonreconstructed patients. Am J Sports Med 2007;35:1135-43.

24. Ardern CL, Webster KE, Taylor NF, et al. Return to sport following anterior cruciate ligament reconstruction surgery: a systematic review and meta-analysis of the state of play. Br J Sports Med 2011;45:596-606.

25. Filbay SR, Crossley KM, Ackerman IN. Activity preferences, lifestyle modifications and re-injury fears influence longer-term quality of life in people with knee symptoms following anterior cruciate ligament reconstruction: a qualitative study. J Physiother 2016;62:103-10.
26. Ardern CL, Taylor NF, Feller JA, et al. A systematic review of the psychological factors associated with returning to sport following injury. Br J Sports Med 2013;47:1120-6.

27. te Wierike SCM, van der Sluis A, van den Akker-Scheek I, et al. Psychosocial factors influencing the recovery of athletes with anterior cruciate ligament injury: a systematic review. Scand J Med Sci Sports 2013;23:527-40.

28. Tjong VK, Murnaghan ML, Nyhof-Young JM, et al. A qualitative investigation of the decision to return to sport after anterior cruciate ligament reconstruction: to play or not to play. Am J Sports Med 2014;42:336-42.

29. Zhang W, Doherty M, Peat G, et al. EULAR evidence-based recommendations for the diagnosis of knee osteoarthritis. Ann Rheum Dis 2010;69:483-9.

30. Roos EM. Joint injury causes knee osteoarthritis in young adults. Curr Opin Rheumatol 2005;17:195-200.

31. Bennell KL, Wrigley TV, Hunt MA, et al. Update on the role of muscle in the genesis and management of knee osteoarthritis. Rheum Dis Clin North Am 2013;39:145-76.

32. American College of Sports Medicine position stand. Progression models in resistance training for healthy adults. Med Sci Sports Exerc 2009;41:687-708.

33. Sousa PL, Krych AJ, Cates RA, et al. Return to sport: does excellent 6-month strength and function following $\mathrm{ACL}$ reconstruction predict midterm outcomes? Knee Surg Sports Traumatol Arthrosc 2015.

34. Roos EM, Lohmander LS. The Knee injury and Osteoarthritis Outcome Score (KOOS): from joint injury to osteoarthritis. Health Qual Life Outcomes 2003;1:64. 